\title{
História, delito e relações de gênero: um panorama sobre o delito de estupro na Europa*
}

\author{
Vanessa Caroline Massuchetto**
}

O desenvolvimento do campo de estudos de história das mulheres desde pelo menos a década de 1970, inserido em um contexto de herança política de movimentos feministas (Tilly, 1994), é já bastante conhecido. Ao longo das décadas foram empreendidos esforços para compreender a complexidade histórica no que tange às personagens femininas afastando-se de conceitos que apenas as descrevam enquanto objeto de análise, aderindo a categorias que auxiliam a posição destas enquanto voz principal da apreciação científica (Scott, 1990). Neste sentido, desenvolveram-se, coligados à história das mulheres, os estudos sobre a história das relações de gênero, mantendo ênfase no caráter social e cultural das distinções baseadas no sexo.

No interior desse cenário, há alguns anos os historiadores, de ambos os sexos, têm cada vez mais direcionado interesses em desvendar questões e problemáticas que englobam mulheres, gênero e justiça em várias temporalidades e espacialidades. Os esforços têm resultado em importantes pesquisas que demonstram a decisiva presença feminina, bem como suas vicissitudes, em espaços que, frente ao silêncio historiográfico e de algumas fontes (Perrot, 2008), estariam destinados a atuação masculina.

O grupo de pesquisadores reunido por Margarita Torremocha Hernández ${ }^{1}$ tem prestado grandes contribuições para a área, sempre com pesquisas de excelência que trazem em seu bojo significativas descobertas. Configura-se em um centro irradiador de importantes trabalhos, nomeadamente sobre o Antigo Regime na Península Ibérica, colaborando com temas de história social, história da cultura jurídica e história do direito. ${ }^{2}$ A presente obra resenhada, El estupro: delito, mujer y sociedad en el Antiguo Régimen, configura-se em um dos resultados do projeto de investigação no qual a equipe trabalhou: Justicia, Sociedad y Mujer en la Edad Moderna a la Contemporaneidad: Castilla, Portugal y Italia. O livro reúne nove investigações de grande envergadura que discutem temáticas acerca do delito de estupro nos espaços correspondentes à Espanha e Portugal ao longo do Período Moderno (compreendendo, também, importantes reflexões acerca do medievo) e à Itália na contemporaneidade.

\footnotetext{
* Recebida em 28 de maio de 2019, aceita em 06 de fevereiro de 2020. Resenha do livro: HERNÁNDEZ, Margarita Torremocha; ALONSO, Alberto Corada (coord.). El estupro: delito, mujer y sociedad en el Antiguo Régimen. Valladolid, Ediciones Universidad de Valladolid, 2018.

** Doutora em História do Direito pela Universidade Federal do Paraná (UFPR), Curitiba, PR, Brasil.vanessa.massuchetto@gmail.com/ https://orcid.org/0000-0003-0390-7890.

1 Doutora em História pela Universidade de Valladolid (1989), professora vinculada ao Departamento de Historia Moderna, Contemporánea, América, Periodismo, Medios de Comunicación Audiovisual y Publicidad e investigadora das linhas de pesquisa em história das universidades hispânicas, história social, história social da delinquência, história da festa pública e história da mulher (Sítio eletrônico do Instituto Universitario de Historia SIMANCAS, Universidad de Valladolid [http://www3.uva.es/simancas/Master_Europeo/profesorado/torremocha_hernandez.htm - acesso em: abril 2019]).

2 Os trabalhos da equipe desenvolvem-se oficialmente desde 2008 (Hernández Torremocha \& Braga, 2015: 7) em sede de projetos de pesquisa financiados pelo Ministerio de Economía y Competitividad, em razão do apoio do Proyectos de Investigación Fundamental, vinculado ao IV Programa Nacional de Investigación Científica, Desarrollo y Innovación Tecnológica. Os projetos de investigação desenvolvidos denominam-seJusticia y Mujer. Los Tribunales Penales en la definición de una identidad de género. Castilla y Portugal (1550-1800) - em atividade entre 2008 a 2011, 2013 a 2016 -e Justicia, Sociedad y Mujer en la Edad Moderna a la Contemporaneidad: Castilla, Portugal y Italia - em atividade de 2017 a 2020. Vinculados aos quais já existem duas publicações: em 2015, As mulheres perante os Tribunais do Antigo Regime na Península Ibérica, sob coordenação de Margarita Torremocha e de Isabel Drumond Braga, e, em 2017, La mujer en la balanza de la justicia (Castilla y Portugal, siglos XVII y XVIII), sob coordenação de Margarita Torremocha e de Alberto Corada Alonso.
} 
As pesquisas abarcam fontes documentais variadas para análise do delito e das personagens nos casos envolvidas, como legislação, informes e doutrina jurídicos, biografias, registros notariais, literatura, cinema, teatro, procedimentos judiciais advindos de jurisdição eclesiástica, régia $e$ privada. ${ }^{3}$ Apresentam uma série de importantes análises acerca do pensamento jurídico; das mudanças legislativas; das cotidianidades; da cultura; das relações comunitárias; sociais; familiares; políticas e institucionais a respeito não somente do delito de estupro, mas também da complexidade englobada pela lógica do matrimônio -tanto pela perspectiva religiosa (configurando-se em uma tônica em várias das relações analisadas em determinadas pesquisas) quanto pelo manejo das questões morais e de honra.

Neste sentido, na apresentação da obra, Margarita Torremocha expõe, especificamente em referência aos processos judiciais, a dimensão que podem oferecer para a visualização dessa complexidade: são eles que deixam entrever em que medida a religião, a honra $e$ a linhagem interferem na ponderação de um magistrado ao mesmo tempo que carregam elementos que discorrem sobre os feitos, os sentimentos, as relações sociais e as cotidianidades.

Ainda em sede destas fontes, explica a autora que o estupro usualmente fora tratado em conjunto (ou confusão) com violação, mancebia, tratos ilícitos e rapto. Assim, clarifica que o delito, segundo a concepção jurídica do Antigo Regime, era delimitado por duas características principais: o engano e a condição de honrada ou de "donzela honesta" da mulher. Ou seja, para a configuração do estupro perante as instituições não era suficiente a violação contra a mulher, mas sim contra a sua virgindade ou a sua honra. Pode-se afirmar, inclusive, que antes de configurar-se um crime contra a integridade física era, principalmente, um crime contra a honestidade. Consequentemente, a discussão processual tocava nomeadamente à perda da virgindade, ao descumprimento à castidade e ao ferimento da honra, situação que disseminava a mácula à família da vítima e até mesmo à comunidade em que vivia.

Exposta esta definição, essencial à compreensão das investigações, passa-se à apresentação dos artigos presentes na obra. O primeiro trabalho ${ }^{4}$ traz à tona um panorama mais geral, no sentido diacrônico, acerca da tratativa do crime em comparação às pesquisas que seguem na obra. $\mathrm{O}$ autor Félix Martínez Llorente possui como enfoque o processo de conceitualização jurídica do delito através da análise legislativa de impacto na tradição europeia. Por meiode uma perspectiva de longa duração, abrange as permanências $e$ as rupturas nas compreensões do delito perpassando pelas disposições do direito romano clássico, do direito visigodo, do direito canônico, da tradição do iuscommune, do direito castelhano do período moderno até os fins do século XVIII.

A conclusão consta expressa já nas primeiras linhas do artigo: o desenvolvimento da definição do estupro foi relativamente tardio sobretudo por ser uma prática que, na apreensão social, transita nas searas do pecado, da moral e do crime. A regulamentação legislativa fora iniciada no direito romano a partir da figura stuprum na lei contrária ao adultério em 18 a.C. no intento de proteção da mulher em razão das justas núpcias e o requisito do engano como diferenciador fora inserido no século III. Este permanecera - não sem diferentes nuances - até transformar-se no requisito principal no Antigo Regime, sobretudo nas experiências dos reinos espanhóis. Em fins do XVIII, salienta o autor, o ajuizamento de causas contra o estupro entrou em decadência, movimento este reforçado pela Real Cédula de 30 de outubro de 1796, que ordenou que não se prendessem mais os acusados. Esse estudo é uma apresentação ampla do panorama histórico a respeito do delito na seara legislativa e seu posicionamento em primeiro no interior da obra ora resenhada auxilia ao leitor na compreensão das investigações que estão na sequência.

A segunda pesquisa porta um cunho quantitativo, e igualmente informativo, como contexto dos trabalhos a seguir, através do qual os autores Alberto Corada Alonso e Diego Quijada Álamo realizam a abordagem do delito no Reino de Castela a partir dos processos mantidos no Arquivo da Real Chancillería de Valladolid. Intitulando-se El estupro en el Antiguo Régimen: una visión cuantitativa desde el Archivo de la Real Chancillería de Valladolid, o trabalho reúne mostra original e total de 2.035 casos ocorridos no espaço castelhano a partir de 1480 até os anos 1830 e a análise

\footnotetext{
3 Insta salientar que seis das nove investigações possuem procedimentos judiciais enquanto documentação história principal.

4 Denomina-se Una notación histórica sobre el delito de estupro hasta la codificación penal.
} 
dos dados é realizada por intermédio de classificações distintas: através da temporalidade, da espacialidade, da competência jurisdicional, da separação entre momentos processuais, do delito (somente estupro e estupro com outra causa), da mulher estuprada (segundo seu estado civil $e$ segundo seu ofício), do estuprador (segundo o grau de parentesco ou relação com a estuprada, dados sobre o ofício e sobre o estado civil) e dos demandantes do processo (se mantinham parentesco com relação à vítima, qual era a profissão do demandante e, por derradeiro, dados a respeito da duração do pleito. Tendo em vista a amplitude do estudo, as conclusões possíveis são, pois, várias. Contudo, demandam o relacionamento dos dados coligidos com pesquisas que adotem o viés qualitativo, ressalva esta que os autores expressam ao final do artigo.

Após esses dois trabalhos panorâmicos, Margarita Torremocha Hernández foca-se na compreensão do pensamento jurídico analisando a dimensão dos discursos como influenciadores do âmbito jurídico processual na definição da identidade do gênero feminino no terceiro capítulo da obra. ${ }^{5}$ A pesquisa objetivou conhecer a mentalidade de Meléndez Valdés a respeito do delito de estupro através de uma visão e um aporte concretos: um informe solicitado à Real Chancelaria de Valladolid em novembro de 1795, requerendo a uniformidade do tratamento processual da matéria, assumido pelo juiz Juan Meléndez Valdés enquanto membro do Tribunal em março de 1796. Após 11 tópicos de argumentações, o jurista concluiu que o foro não deveria dar conhecimento a esses casos, forçando as mulheres a cuidarem de si mesmas e a guardarem sua honestidade. Em seguida, foi publicada a Cédula Real de 30 de outubro de 1796 - que, segundo Llorente, fora uma das razões da decadência de denúncias de estupro no XVIII -, acatando dois dos argumentos de Valdés: a redução do aprisionamento e o estabelecimento do limite de idade de 25 anos da vítima como requisito de enquadramento no delito. Em que pese o informe não tenha impactado a ordem jurídica espanhola de fins do século XVIII a ponto de realizar amplas reformas imediatas, Torremocha salienta que representa um elemento chave por ter sido um dos juristas preocupados em delimitar o crime de estupro e estabelecer um marco legislativo novo. Assim, sua perspectiva, e consequentemente seu discurso, absorve muitas das visões circulantes no período, sendo representativa das mudanças que ocorrem na cultura jurídica de fins do Antigo Regime.

A título de exemplo, é importante citar a defesa de Valdés à limitação embasada na faixa etária da mulher estuprada. A discussão a respeito das idades dos envolvidos e seus desdobramentos encontrava-se em circulação na Península Ibérica e em Portugal havia sido introduzida uma limitação já em 1603 pelas Ordenações Filipinas (Livro V, tít. XXIII, §2). De acordo com essa compilação, no tocante à prescrição para ingresso de querela, a determinação era que o ajuizamento deveria ocorrer dentro do período de um ano contado a partir da data em que se deixava de ter afeição entre as pessoas envolvidas no delito, sendo que este prazo somente poderia ser elastecido caso a vítima fosse menor de 25 anos ou comprovasse impedimento de denunciação em período anterior.

Na sequência da obra ora resenhada, o trabalho de autoria de José Pablo Blanco Carrasco ${ }^{6}$ traz à tona uma perspectiva metodológica micro, realizando um estudo mais aproximado $e$ qualitativo de casos selecionados. O foco centra-se na tratativa do delito por tribunais eclesiásticos, bem como a relação das personagens envolvidas no crime com a comunidade através do mercado matrimonial, a partir dos processos coletados no Arquivo Diocesano de Sigüenza e no Arquivo Diocesano de Ciudad Rodrigo.

Ambientado pelos cenários apresentados nos artigos precedentes, tanto no que tange à diacronia legislativa quanto na numeração quantitativa e na inserção da atmosfera mental apresentada, o autor verticaliza a análise no interior das práticas e compreensões do supracitado mercado apontando conclusões na seara da história social. Assim, afirma que a regra imperante nas dinâmicas estudadas era a semelhança ou igualdade entre as famílias envolvidas ${ }^{7}$ e a ocorrência de

\footnotetext{
${ }^{5}$ Intitulado El estupro en el Informe jurídico de Meléndez Valdés. Una visión ilustrada de un delito contra el honor familiar (1796).

6 Intitulado "Adónde irán los secretos?” Reflexiones en torno al estupro y el mercado matrimonial en la Edad Moderna.

7 Para que isso pudesse ser auferido, eram observados a honra provada do grupo familiar (representando a honestidade da mulher que vai contrair o casamento), o peso público das famílias, medido normalmente pela participação em ofícios de república, o respeito à justiça, o pertencimento a grupos sociais de boa estima e, cada vez mais com maior peso mas
} 
um caso de estupro era um fator demolidor da integridade da estima social da família. Ou seja, a prática era enfrentada como um delito político e, no interior dos casos trazidos à luz por Carrasco, a projeção comunitária acarretava a quebra das chances de casamento das mulheres pertencentes à mesma família. Um elemento que pode servir de meio para uma explicação à extensão da mácula era o fato de que, no âmbito das relações pré-nupciais, a ocorrência de um estupro dava ensejo ao debate acerca do consentimento não forçado de uma mulher, mesmo que houvesse violência moral.

Nesse ponto, as questões supracitadas nos trabalhos precedentes a respeito da conceitualização do delito, a partir da ocorrência do engano na experiência espanhola, adquire reproduções no social. Isso é, o engano poderia ser visto como violência moral, porém no seu interior ainda havia o consentimento da mulher estuprada na ocorrência do delito. A existência deste consentimento significava que a mulher teria o direito a utilizar livremente de sua vontade neste terreno, cedendo à sedução quando lhe aprouvesse. Em agindo uma mulher da família, desse modo, vinculavam-se a este os comportamentos das demais, gerando um amplo impacto social da ocorrência do delito nas dinâmicas comunitárias com relação à família.

Isabel Drumond Braga, autora da quinta investigação constante da obra ${ }^{8}$, traz ao estudo a contribuição acerca de Portugal moderno e salienta uma das características mais importantes acerca da justiça portuguesa do Antigo Regime: a dimensão da misericórdia, da clemência e do perdão. Para o vislumbre dessa nuance, as fontes principais da investigação são as cartas de perdão, redigidas por sujeitos condenados pelos magistrados (mas que receberam o perdão das suas vítimas) requerendo exclusão (ou comutação) da aplicação da pena e encaminhadas à apreciação régia. Com a finalidade de aporte contextual, a autora realiza análise de excertos literários e da legislação portuguesa da época sobre o delito (com menções a determinadas normas vindas do medievo) vislumbrando a tratativa formal, suas permanências e descontinuidades no tempo e no espaço.

Assim, conclui que também em Portugal moderno o estupro correspondia a um delito grave, do foro moral, cuja proteção era do pudor e a defesa era da virgindade. As diferentes tonalidades das aplicações dos procedimentos e da circulação de mentalidades, além da análise social, são ensejadas pelo estudo das cartas de perdão, considerando que possibilitam a reconstrução de vários cenários crimes de violação. Ao mesmo tempo em que trazem descrições de casos em que mulheres foram forçadas violentamente, há também alusão a seduções enganosas e falsas promessas de casamento - situações estas que podem vir a camuflar casos de violação. Processados os casos, diversas razões faziam com que, na prática, os ofensores restassem impunes: para além dos pedidos de perdão obtidos, a autora menciona a cominação de pena mais branda que a ordenada pela legislação (o que não significava a execução também dessa pena), a ausência de julgamento no caminhar processual e a própria disparidade entre o número de ocorrências $e$ a institucionalização de denúncias e queixas. Nessa esteira, conclui que a violação era, em maior ou menor medida, efetivamente perseguida, porém o castigo não era uma prática eficaz.

Entre os pontos abordados, é possível relacionaras experiências apresentadas em diferentes espacialidades, mesmo que os trabalhos demonstrem uma diferença entre Espanha e Portugal no que tange à existência do engano. As fontes sugerem que nas ocorrências do delito nos espaços espanhóis a sedução era um requisito de certa forma mais taxativo que nas práticas portuguesas. Isso é, os elementos que o engano envolvia eram, certamente, tomados em conta no momento da decisão em sede das cartas de perdão, todavia não há a sugestão de que foram estritamente necessários no momento da condenação dos sujeitos pelo crime, situação diferente daquelas abordadas nas práticas castelhanas. Nestas experiências, o engano aparentemente adquiria vestes de instituto jurídico enquanto requisito necessário para a configuração do delito.

Enfocando os estudos na espacialidade aragonesa, na sexta investigação ${ }^{9}$ Encarna Jaque Martínez realiza um aporte geral focado nas práticas institucionais sobre a tratativa acerca do delito.

não de modo conclusivo, a renda e as possessões materiais, que podem melhorar as deficiências da casa mas sem diluí-las completamente.

8 Denominada Punir a Violação, perdoar os Violadores: entre a justiça e a clemência no Portugal Moderno.

9 Denominada "Y sobre todo pido justicia": el delito de estupro en Aragón (siglos XVI y XVII). 
A autora perpassa o estudo pelas legislações aragonesas medieval e moderna no intuito de contextualizar os casos de sua fonte principal: os processos por estupro mantidos no Arquivo Diocesano de Zaragoza e no Arquivo Histórico Provincial de Zaragoza. A análise desta documentação é realizada a partir da classificação entre estupros puros ou simples (em que há a violação de "donzela"), aqueles em que o tipo criminal se mescla com outros crimes (casos em que os argumentos jurídicos utilizados na prática dos foros contribuíam para a ausência de clarificação a respeito do estupro) e aqueles conseguidos através de palavra de casamento.

A autora expõe que aparentemente o tribunal secular apresentava maior tolerância à conduta masculina que à feminina, enquanto o tribunal eclesiástico mantinha procedimentos mais respeitosos e sensíveis à mulher, sendo mais favorável ao matrimônio. No primeiro, a responsabilização pela ocorrência do crime era majoritariamente depositada sobre a mulher e sua desonestidade, argumento básico que ensejava a exclusão de pena ao homem através da compreensão de que a negligência feminina não poderia ocasionar punição masculina. No segundo, havia atenção à frequente desigualdade social entre as partes, motivo pelo qual, segundo a autora, as sentenças findavam por ser mais abertas à possibilidade do matrimônio ou do dote.

Os apontamentos específicos acerca do ramo eclesiástico vão de encontro com os estudos de Daniel Baldellou Monclús e José Antonio Salar Auséns no sétimo capítulo ${ }^{10}$, em que enfocam especificamente os processos de tribunais eclesiásticos aragoneses. Ao longo do texto apresentam semelhanças e diferenças entre os tratamentos secular e eclesiástico, afirmando, sumariamente, que a visão eclesiástica era constituída a partir do matrimônio (por esta razão algumas vezes eram mesclados com casos de esponsais não cumpridos) enquanto que a tratativa civil mantinha maior atenção à honra e ao patrimônio (a maioria dos casos levados a estes tribunais estavam frequentemente relacionados a violações e agressões). Analisando as sentenças dos casos selecionados, os autores afirmam que a ponderação mantinha em consideração o relacionamento entre o homem e a mulher envolvidos - se havia contatos prolongados no tempo, se fora realizada uma promessa de casamento, se houve coação ou violação -, o que resultava na possibilidade de pagamento de dote compensatório. Às mulheres vitimadas, a ocorrência de um estupro era um fator de quebra de posição social, e receber a sentença eclesiástica favorável a si significava alguma recuperação no interior do tecido social. Assim, afirmam os autores, os interesses se cruzavam: de um lado o desejo de controle de uniões constituídas de modo alheio à ordem social e, de outro, o desejo de restauração da honra, após uma situação de violação e humilhação em que socialmente a culpabilização recaía sobre a mulher. Os tribunais eclesiásticos, concluem, representavam um importante recurso de resposta a estas mulheres.

A oitava investigação ${ }^{11}$, de autoria de Tomás A. Mantecón Movellán, é realizada a partir da análise de experiências e trajetórias particulares em sociedades católicas do Mediterrâneo, tendo os processos judiciais como documentação histórica principal. A classificação da investigação segue a divisão entre subcapítulos ${ }^{12}$, realizada a partir da conexão entre os casos encontrados nos procedimentos judiciais. A partir destas análises, o autor sublinha que os processos demonstram as tolerâncias sociais, institucionais e governativas, a assimetria dos gêneros nos impulsos sexuais e de poder e o impacto das diferentes culturas ao longo do espaço Mediterrâneo. Conclui, assim, com apontamentos para a seara social a partir das evidências da documentação sobre as capacidades dos sujeitos no interior de seus cenários sociais particulares, para negociação e renegociação de relações sexuais, conjugais e sociais. O estupro, sendo considerado em situações complexas, era um delito que se encontrava em amplo relacionamento com as redes de poder articuladas, e este apontamento conecta-se de modo direto com as citadas conclusões de José Pablo Blanco Carrasco

\footnotetext{
${ }^{10}$ Intitulado Culpable hasta que se demuestre lo contrario: el estupro ante los tribunales eclesiásticos de Aragón en el siglo XVIII.

${ }^{11}$ Denominada Estupro, sexualidad e identidad en sociedades católicas del Mediterráneo durante el Antiguo Régimen,

${ }^{12}$ Quais sejam, o estupro e maus usos da promessa matrimonial, evidenciando as possibilidades de estabelecimento de algum tipo de relação entre os personagens envolvidos com ou sem um expresso pacto de ajuda mútua; o poder e a pressão social que permeiam muitos casos de estupro, sublinhando as negociações entre as partes em sede processual bem como o diálogo com as instituições judiciais, os familiares e os entornos sociais; por derradeiro, a mobilidade geográfica, os usos da sexualidade e do matrimônio como meios de empreender rupturas e novas relações em diferentes espacialidades.
} 
acerca do mercado matrimonial na Idade Moderna. Isto é, a ocorrência do crime fazia parte de um grande manejo de situações sociais e comunitárias, englobando a noção de representar um delito político.

A última investigação constante desta obra altera o foco da Península Ibérica para a Itálica $e$ ambienta-se na história contemporânea. Daniela Novargese, autora do artigoLa giustizia era altrettanto violenta degli stupratori. Donne e violenzasessuale in Italia, un lungo, tormentatopercorso normativo, conduz as análises a partir de casos, de manifestações culturais e de movimentos políticos ocorridos na Itália entre os anos 1965 e 1996 que detiveram ampla repercussão e que em maior ou menor medida geraram impacto na sociedade italiana a ponto de culminar nas alterações legislativas ocorridas no Código Penal Italiano em 1996. Inicia discorrendo sobre os casos de Franca Viola ${ }^{13}$, em 1965, e de Rosaria Lopez e Donatella Calosanti ${ }^{14}$, em 1975, pela atenção nacional que detiveram. Em razão do impacto provocado, assumiram contornos paradigmáticos e simbólicos no imaginário coletivo social, abriram espaços de discussão acerca do crime de estupro bem como ensejaram o início de proposições de reforma legislativa em 1977 pela deputada Angela Maria Bottari. Estas proposições, acrescidas de manifestações culturais e políticas de mulheres nas décadas de 70, 80 e 90, foram importantes para que em 1996 fossem realizadas algumas reformas no texto legislativo, incluída a alteração de título do crime de estupro: de Delitos contra a moralidade pública e o bom costume para Dos delitos contra a pessoa. Embora não completamente satisfatória, a alteração foi politicamente necessária no sentido do alcance do consenso. A inserção do crime em outro título, conclui a autora, representou muito mais do que simplesmente alteração de título no interior do código penal. Foi a alteração do próprio bem jurídico tutelado: antes era a moral, a partir de 1996 passou a ser a pessoa ofendida, fazendo com que a liberdade sexual constituísse um corolário insuprimível da pessoa individual.

O título da presente obra, El estupro: delito, mujer y sociedad en el Antiguo Régimen, por amplo, abarca bem o conteúdo da maior parte dos artigos nela coligidos à exceção da derradeira investigação por não se aproximar absolutamente às questões de Antigo Regime. No tocante ao esforço das pesquisas em abordar as temáticas relacionadas ao "delito", "mulher" e "sociedade", acredita-se que logrem êxito tendo em vista que todas possuem um aporte muito rico de informações $e$ análises destes três elementos a partir de diferentes perspectivas metodológicas. $\mathrm{O}$ equilibrio aparenta pender mais ou menos para o delito em razão de abordagens exclusivamente legislativas em determinadas passagens de alguns estudos, porém em nada prejudica as conclusões $e$ as conexões com o social. A respeito dos elementos "mulher" e "sociedade" é importante mencionar que a plenitude da abordagem desenvolvida pelos pesquisadores trabalha com a categoria de gênero, tendo em vista a consideração, a todo tempo, das relações entre homens $e$ mulheres - ensejada até mesmo em decorrência da própria definição do delito nos períodos analisados.

Por fim, cabe salientar que a obra representa valiosa produção dos investigadores envolvidos, trazendo em seu bojo importantíssimas reflexões e construções do conhecimento à história das relações de gênero; à história das mulheres; à história social; à história cultural; à história da cultura jurídica e à história do direito. Demonstram as complexidades englobadas pelo delito de estupro aos níveis social, institucional e cultural, evidenciando as profundidades das questões de gênero e proporcionando ao leitor o conhecimento de uma documentação rica, variada e relevante.

\section{Referências bibliográficas}

PERROT, Michelle, Minha história das mulheres. São Paulo, Contexto, 2008.

\footnotetext{
${ }^{13}$ Franca Viola foi raptada e estuprada pelo ex namorado em 1965, momento em que a existência de matrimônio excluía a possibilidade de o cônjuge ser enquadrado no crime de estupro e em que existiam muitos casos de rapto embasado em sedução, solucionado com núpcias reparadoras. Franca Viola negou os instrumentos legislativos vigentes colocados à disposição na busca de tutelar a honra feminina.

${ }^{14}$ Rosaria Lopez e Donatella Calosanti foram sequestradas e estupradas por três homens. Rosaria Lopez perdeu a vida em decorrência da violência sofrida. Donatella Calosanti conseguiu livrar-se e acusou, com muita dificuldade, os violentadores através de um processo decorrido entre 30 de junho e 29 de julho de 1976.
} 
PORTUGAL. Ordenaçóes Filipinas. Livro V. $14^{\mathrm{a}}$ ed. (Recompiladas por Candido Mendes de Almeida segundo a primeira de 1603 e a nona de Coimbra de 1821). Rio de Janeiro, Typographia do Instituto Philomathico.

SCOTT, Joan. Gênero: uma categoria útil de análise histórica. Educação e Realidade. Porto Alegre, Faculdade de Educação da UFRGS, v. 16, n. 2, jul./dez. 1990, pp.5-22.

TILLY, Louise A. Gênero, história das mulheres e história social. cadernos pagu (3), Campinas-SP, Núcleo de Estudos de Gênero-Pagu/Unicamp, 1994, pp.29-62.

TORREMOCHA HERNÁNDEZ, Margarita \& ALONSO, Alberto Corada. La mujer en la balanza de la justicia (Castilla y Portugal, siglos XVII y XVIII). Valladolid, Castilla Ediciones, Colección Historia, 2017.

TORREMOCHA HERNÁNDEZ, Margarita \& BRAGA, Isabel Drumond. As mulheres perante os Tribunais do Antigo Regime na Península Ibérica. Coimbra, Imprensa da Universidade de Coimbra, 2015. 